\title{
Salmonella contamination, serovars and antimicrobial resistance profiles of cattle slaughtered in South Africa
}

\begin{tabular}{|c|c|}
\hline $\begin{array}{l}\text { Authors: } \\
\text { Evelyn Mador } \\
\text { Daniel Kapeta } \\
\text { Awoke K. Gela }\end{array}$ & $w^{1}$ \\
\hline $\begin{array}{l}\text { Affiliations: } \\
{ }^{1} \text { Bacteriology } \\
\text { Agricultural R } \\
\text { Council-Onde } \\
\text { Veterinary Ins } \\
\text { Africa }\end{array}$ & $\begin{array}{l}\text { Section, } \\
\text { search } \\
\text { stepoort } \\
\text { itute, South }\end{array}$ \\
\hline $\begin{array}{l}{ }^{2} \text { College of } \mathrm{Ag} \\
\text { Environmenta } \\
\text { University of } \\
\text { Florida Campi }\end{array}$ & $\begin{array}{l}\text { iculture and } \\
\text { Sciences, } \\
\text { outh Africa, } \\
\text { s, South Africa }\end{array}$ \\
\hline $\begin{array}{l}\text { Research Proj } \\
\text { 000791-Y5 }\end{array}$ & ect no.: \\
\hline $\begin{array}{l}\text { Correspondin } \\
\text { Evelyn Mador } \\
\text { madorobae@ }\end{array}$ & $\begin{array}{l}\text { author: } \\
\text { oba, } \\
\text { arc.agric.za }\end{array}$ \\
\hline $\begin{array}{l}\text { Dates: } \\
\text { Received: } 021 \\
\text { Accepted: } 25 \\
\text { Published: } 26\end{array}$ & $\begin{array}{l}\text { lov. } 2015 \\
\text { an. } 2016 \\
\text { May } 2016\end{array}$ \\
\hline $\begin{array}{l}\text { How to cite th } \\
\text { Madoroba, E., } \\
\text { Gelaw, A.K., } 2 \\
\text { 'Salmonella cc } \\
\text { serovars and } \\
\text { resistance pro } \\
\text { slaughtered in } \\
\text { Onderstepoor } \\
\text { Veterinary Res } \\
\text { a1109. http:/ } \\
\text { org/10.4102/ }\end{array}$ & $\begin{array}{l}\text { is article: } \\
\text { Kapeta, D. \& } \\
16 \text {, } \\
\text { ntamination, } \\
\text { ntimicrobial } \\
\text { files of cattle } \\
\text { South Africa', } \\
\text { Journal of } \\
\text { earch 83(1), } \\
\text { dx.doi. } \\
\text { jvr.v83i1.1109 }\end{array}$ \\
\hline $\begin{array}{l}\text { Copyright: } \\
\text { (C) 2016. The } \\
\text { Licensee: AOS } \\
\text { is licensed unc } \\
\text { Creative Comr } \\
\text { Attribution Lic }\end{array}$ & $\begin{array}{l}\text { uthors. } \\
\text { S. This work } \\
\text { ler the } \\
\text { nons } \\
\text { ense. }\end{array}$ \\
\hline Read online: & \\
\hline 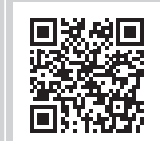 & $\begin{array}{l}\text { Scan this QR } \\
\text { code with your } \\
\text { smart phone or } \\
\text { mobile device } \\
\text { to read online. }\end{array}$ \\
\hline
\end{tabular}

Antimicrobial resistant Salmonella are among the leading causes of foodborne infections. Our aim was to determine Salmonella contamination during cattle slaughter in South African rural abattoirs $(n=23)$ and environmental samples. Furthermore, antimicrobial resistance patterns of the Salmonella isolates were determined. Samples of cattle faeces $(n=400)$, carcass sponges $(n=100)$, intestinal contents $(n=62)$, hides $(n=67)$, and water from the abattoirs $(n=75)$ were investigated for Salmonella species using microbiological techniques and species-specific polymerase chain reaction targeting the invA gene. In total 92 Salmonella species isolates were recovered. The Salmonella mean frequency of occurrence on hides, carcasses, and intestinal contents was $35.37 \%(n=81)$. Eleven faecal samples $(2.75 \%)$ tested positive for Salmonella. The predominant serovar was Salmonella Enteritidis. Diverse serovars that were identified on carcasses were not necessarily found on the hides and intestinal contents. The inconsistent occurrence of the diverse Salmonella serovars on hides, carcasses, and intestinal contents implies that in addition to carriage on hides and in intestinal contents, other external factors also play an important role regarding carcass contamination. The 92 Salmonella were serotyped and tested for susceptibility towards the following antimicrobials: ampicillin, cefotaxime, enrofloxacin, kanamycin, and oxytetracycline using the disk diffusion method. Most Salmonella $(n=66 ; 71.7 \%)$ isolates were resistant to at least one antimicrobial with highest resistance observed towards oxytetracycline (51.90\%), which highlights the need for strict hygiene during slaughter and prudent antimicrobial use during animal production. In conclusion, cattle slaughtered in South African rural abattoirs harbour diverse Salmonella serovars that are resistant to antimicrobials, which could be a public health risk. The findings should assist policymakers with improving implementation of hygienic slaughter of cattle in rural abattoirs, which is paramount from socioeconomic, public health, and epidemiological standpoints.

\section{Introduction}

Bacteria are among the leading causes of foodborne illnesses (Buzby \& Roberts 2009). Foodborne outbreaks result in socioeconomic challenges as a result of hospitalisations and associated medications, particularly among the vulnerable groups such as the elderly and immunocompromised individuals (Gragg et al. 2013). Among the bacteria, Salmonella has been frequently linked to gastroenteritis worldwide (Skov et al. 2007). Salmonella causes salmonellosis, which is characterised by nausea, abdominal pain, diarrhoea, and sometimes fever that results in morbidity and in some instances mortality in both animals and human beings (Nørrung \& Buncic 2008; Velge, Cloeckaert \& Barrow 2005). A study by Majowicz et al. (2010) found that, globally, Salmonella infection is responsible for an estimated 93.8 million cases of human gastroenteritis and 155000 fatalities annually.

Salmonella has been associated with a number of food-producing animals, which makes animals and their products important sources of human infections (Acha \& Szyfres 2001; Davies, Dalziel \& Gibbens 2004). The risk of Salmonella contamination may be present at any stage of food animal production ranging from the live animal to environmental factors (Alexander, Warnick \& Wiedmann 2009; Troutt \& Osburn, 1997). At the farm level, cattle hides may become exposed to Salmonella through contact with contaminated faeces, feed, or the environment, which poses a risk to food safety if these organisms are transferred on the carcass during slaughter (Arthur et al. 2007; BrichtaHarhay et al. 2008). Cattle may also be contaminated with Salmonella during transportation through contact with faeces of other animals. During slaughter, some procedures such as evisceration and splitting may contribute to carcass contamination (Hui 2012). This is exacerbated by the asymptomatic carrier status of some cattle, which may pose a risk along the food chain (Fegan et al. 2005; Tadesse \& Tessema 2014). Therefore, some of the sources of Salmonella contamination are already present well before the animals are presented for slaughter. In this regard, strict hygienic processes during slaughter procedures are paramount in order to reduce the chances of meat contamination. 
In South Africa, the Meat Safety Act (No. 40 of 2000) provides for specific requirements on how red meat abattoirs should slaughter cattle. However, in some rural abattoirs meat inspection may not be routinely carried out, which often compromises safe meat handling. This potentially exposes rural communities to various foodborne pathogens including Salmonella spp. There is paucity of information regarding prevalence of diseases and hygiene measures taken during cattle slaughter among communal cattle producers. Therefore, it is imperative to obtain such information for better understanding of the potential risk of spreading Salmonella from cattle slaughtered in rural abattoirs through the food chain and to institute proper and relevant situationspecific management strategies for foodborne diseases.

The prevalence of antimicrobial resistance among foodborne pathogens has increased during recent decades (Economou \& Gousia 2015). The increase in antimicrobial resistance among Gram-negative bacteria such as Salmonella may be attributed to the overuse of antimicrobials in food-producing animals for growth promotion, treatment of infection, or for prophylaxis (Economou \& Gousia 2015). In South Africa, the Fertilizers, Farm Feeds, Agricultural Remedies, and Stock Remedies Act (Act 36 of 1947) makes provision for antimicrobial administration in animals (Henton et al. 2011). This allows individuals such as farmers to access stock remedies over the counter (Henton et al. 2011), which may contribute to antimicrobial overuse. However, the Medicines and Related Substances Control Act (Act 101) also controls veterinary medicines whereby antimicrobials for animal use are only prescribed by a veterinarian (Henton et al. 2011).

There is limited information regarding Salmonella contamination of carcasses by hides and intestinal contents during cattle slaughter in South African rural abattoirs. Information about antimicrobial resistance of Salmonella isolates recovered from cattle in South African rural communities is scant. This study was aimed at contributing to knowledge about the extent of contamination of cattle carcasses by hides and intestinal contents during slaughter and antimicrobial resistance of the Salmonella isolates. The objectives of this study were therefore to determine the presence and serovar diversity of Salmonella on cattle hides, carcasses, and intestinal contents of cattle slaughtered in rural abattoirs $(n=23)$ of Vhembe district in Limpopo Province of South Africa. In addition, the occurrence of Salmonella spp in water samples (used in abattoirs) and fresh cattle faeces from communities that supply rural abattoirs with animals for slaughter was determined in a parallel study. Furthermore, antimicrobial resistance patterns of the Salmonella isolates recovered from slaughtered cattle and environmental samples were determined.

\section{Materials and methods}

\section{Study area and design}

Vhembe district municipality is located in the northern part of Limpopo Province of South Africa and it comprises four local municipalities; namely Mutale, Musina, Makhado, and
Thulamela. In this study, samples were collected from cattle slaughtered in rural abattoirs of Vhembe district from all the four local municipalities. A cross-sectional study involving 23 rural abattoirs that slaughter cattle was conducted between March 2011 and April 2012. To our knowledge, these represent all the rural abattoirs that had permission to slaughter cattle in Vhembe district during the study period. The names of the abattoirs have been withheld for confidentiality.

Cattle for slaughter at the rural abattoirs were obtained from farms in any of the four local municipalities of Vhembe district. In addition, some of the cattle were brought for slaughter by community members in preparation for events such as weddings, funerals, or other important family functions. The study targeted collection of matched 100 hide samples, 100 carcass swabs, and 100 rectal swabs. The sample size was determined using the following formula described in the European Food Safety Authority (EFSA) Report on 'Development of harmonised survey methods for foodborne pathogens in foodstuffs in the European Union' (Käsbohrer et al. 2010):

$n_{\infty}=\frac{\left(Z_{\alpha}\right)^{2} * p^{*}(1-p)}{L^{2}}$

[Eqn 1]

Where $n=$ sample size; $Z_{\alpha}=$ desired confidence level at $95 \%$ (equivalent to $Z_{\alpha}$ value of 1.96); and $L=$ Accuracy, which was set at 0.05 in this study; $p=$ annual expected prevalence.

The annual expected Salmonella prevalence in South African cattle is not formally documented, hence an approximate prevalence of $18.75 \%$, which was based on a retrospective study by Kidanemariam, Engelbrecht and Picard (2010) was used in this study. Assuming a prevalence of $18.75 \%$, the estimated sample size is 234 , hence this study targeted 300 samples from cattle hides, carcasses, and intestinal contents.

A parallel study involving collection of freshly voided cattle faeces $(n=400)$ was carried out in order to ascertain the possible risk of Salmonella shed by cattle in Vhembe district communities and to obtain information about asymptomatic animals that had potential of contaminating carcasses during slaughter. Sample size was also based on the assumptions that were made for slaughtered cattle. Water samples used in the abattoirs $(n=75)$ were also analysed for the presence of Salmonella.

\section{Sample collection}

\section{Carcasses}

Samples were collected from carcasses $(n=100)$ using premoistened commercial beef Carcass Sampling polywipe Kits (ThermoFischer Scientific, Waltham, MA, USA) as described in the United Kingdom Meat Industry Guide. Using a sweeping motion, the sponge was rubbed firmly across the carcass from the hind quarter covering an area of $1000 \mathrm{~cm}^{2}$ per carcass. The polywipe sponge was placed in a sample bag, labelled appropriately and kept cool (but not frozen) by immediately placing in insulated cooler boxes 
containing frozen freezer blocks and transported to the Feed and Food Analysis laboratory, Bacteriology Section of the Agricultural Research Council-Onderstepoort Veterinary Institute (ARC-OVI).

\section{Hides}

Samples were collected from external hide surfaces $(n=67)$ by rubbing using a premoistened sterile sponge covering $500 \mathrm{~cm}^{2}$. Briefly, sterile square metal templates covering $100 \mathrm{~cm}^{2}$ areas were placed onto hides and two sponges were used to swab five consecutive areas (Antic et al. 2010). Each sponge was placed in a separate stomacher bag and transported to the ARC-OVI Feed and Food Analysis laboratory within $24 \mathrm{~h}$.

\section{Intestinal contents}

Intestinal contents $(n=62)$ were collected from the slaughtered animals and the samples were placed in sterile containers. The containers were immediately placed in cooler boxes containing frozen freezer packs.

\section{Water}

Water samples used in the abattoirs $(n=75)$ were collected according to instructions in the Water Research Commission No TT117/99 (2000). Briefly, the tap was opened and water was allowed to run for $3 \mathrm{~min}$, followed by filling sterile bottles to about three quarters full. The bottles containing water were immediately placed in cooler boxes containing frozen freezer packs.

\section{Faeces}

Freshly voided faeces $(n=400)$ from cattle in the local communities were collected in sterile containers as a parallel study to determine the potential risk of Salmonella during slaughter and among inhabitants of Vhembe district.

\section{Microbiological analysis}

\section{Salmonella isolation and identification}

For carcass and hide sponges, the samples were mixed thoroughly with maximum recovery diluents. The fluid mixture from the hide and carcass sponges $(25 \mathrm{~mL})$ was inoculated into $225 \mathrm{~mL}$ of non-selective pre-enrichment liquid medium containing buffered peptone water (BPW) supplemented with 1\% Tween 80 (1:10 v/v). For cattle faeces and intestinal contents, $10 \mathrm{~g}$ samples were inoculated into $90 \mathrm{~mL}$ of BPW supplemented with $1 \%$ Tween 80 . The inoculated BPW was incubated aerobically at $37^{\circ} \mathrm{C}$ for $18 \pm$ $2 \mathrm{~h}$. After incubation, 1-mL aliquots of the samples from BPW were inoculated into Rappaport-Vassiliadis soy broth (RVS) and Tetrathionate broth (MKTT) (RV; Merck, Darmstadt, Germany), followed by incubation at $42{ }^{\circ} \mathrm{C}$ for $24 \mathrm{~h}$. Loopfuls of the broth were plated onto Xylose Lysine Desoxycholate agar (XLD), RapidSal, and Brilliant Green agar (BGA), followed by incubation at $37{ }^{\circ} \mathrm{C}$ for $24 \mathrm{~h}$. The plates were examined for the presence of typical Salmonella colonies and further identified on the basis of biochemical tests. Isolates that were positive for lysine decarboxylase, were motile, did not produce urease, produced hydrogen sulfide on triple sugar iron agar, fermented dulcitol, and had variable reactions to mannitol were identified as Salmonella spp.

Isolation of Salmonella from water samples was adopted from the Standing Committee of Analysts (2002; Hammarstrom \& Ljutov 1954). Briefly, the bacteria in water were concentrated by passage through membrane filters. The membrane filters were transferred into BPW, followed by incubation at $37^{\circ} \mathrm{C}$ for $18 \pm 2 \mathrm{~h}$. A portion of broth $(10 \mathrm{~mL})$ was transferred into enrichment selective media $(90 \mathrm{~mL})$, followed by subculture onto XLD, RapidSal, and BGA. The plates were incubated at $37{ }^{\circ} \mathrm{C}$ for $24 \mathrm{~h}$ and examined for colonies that are typical of Salmonella species.

For all samples, internal quality control was performed in parallel with the test samples and involved the use of Salmonella Typhimurium ATCC14028 as positive control and Escherichia coli ATCC 25922 as a negative control. In addition, for water samples, blank control filters containing sterile distilled water $(100 \mathrm{~mL})$ and Ringer's lactate solution were included. This was done after normal sterilisation of the filtration unit.

Colonies that were pink and black centred on XLD, pink on BGA, and purple on RapidSal agar (Merck, Darmstadt, Germany) were considered typical of Salmonella spp and were subcultured onto blood tryptose agar (BTA), followed by incubation at $37^{\circ} \mathrm{C}$ for $24 \mathrm{~h}$. The pure cultures were confirmed using the following biochemical tests: Triple sugar iron agar, urea agar, malonate broth, phenol red dulcitol broth, lysine decarboxylase broth, decarboxylase broth control, and thiogelatine semisolid agar to test for motility. Escherichia coli ATCC 25922 and Salmonella Typhimurium ATCC 14028 were included as negative and positive controls respectively. Isolates that were confirmed as Salmonella were preserved in nutrient broth supplemented with $35 \%$ glycerol and stored at $-20{ }^{\circ} \mathrm{C}$ for subsequent species-specific polymerase chain reaction (PCR), antimicrobial susceptibility testing, and serotyping.

\section{Salmonella Serotyping}

Salmonella serotyping was done as prescribed in the Kauffman-White scheme. Briefly, the Salmonella isolates were tested against polyvalent and monovalent antisera for the presence of agglutination. The bacteria were tested for the presence of somatic $(\mathrm{O})$ antigens, flagellar $(\mathrm{H})$, and $\mathrm{Vi}$ antigens.

\section{Antimicrobial susceptibility test}

Salmonella isolates $(n=92)$ were tested for antimicrobial susceptibility towards the following antimicrobial agents: ampicillin (AMP), cefotaxime (CXT), enrofloxacin (ENR), kanamycin (K), and oxytetracycline (OT) using the KirbyBauer disk diffusion method. Briefly, the Salmonella spp were suspended in physiological saline until the turbidity was equivalent to $0.5 \mathrm{McF}$ arland standard. The bacterial 
suspensions were inoculated onto Mueller Hinton agar, and disks were placed on the inoculated agar. The inoculated plates were incubated at $37^{\circ} \mathrm{C}$ for $24 \mathrm{~h}$. The inhibition zones were measured using calipers and results were interpreted as sensitive, intermediate, or resistant according to Clinical Laboratory Standards. The reference strains of E. coli ATCC 25922 and Salmonella Typhimurium ATCC 14028 were included alongside the field isolates.

\section{Molecular identification}

The PCR was used to confirm identification made by phenotypic tests.

\section{DNA extraction}

The Salmonella isolates were resuscitated by inoculation into nutrient broth, followed by incubation at $37{ }^{\circ} \mathrm{C}$ for $2 \mathrm{~h}$. Loopfuls from the nutrient broth were streaked onto nutrient agar, followed by incubation at $37^{\circ} \mathrm{C}$ for $24 \mathrm{~h}$. The DNA was extracted from Salmonella colonies using the cell lysis method. Briefly, Salmonella cells were suspended in $1 \mathrm{~mL}$ of sterile distilled water. The bacterial suspensions were boiled at $99{ }^{\circ} \mathrm{C}$ for $10 \mathrm{~min}$, followed by cooling at room temperature and centrifugation at $13000 \mathrm{rpm}$ for $5 \mathrm{~min}$. The supernatants were transferred into clean sterile eppendorf tubes and debris was discarded. The crude supernatant was used as DNA template in the PCR reactions.

\section{Polymerase chain reaction}

The 25- $\mu \mathrm{L}$ PCR reactions contained $12.5 \mu \mathrm{L}$ DreamTaq master mix (Fermenats; Ontario, Canada), $10 \mu \mathrm{M}$ of each primer targeting the invA gene (invAF-5'-GTGAAATTATCGCCAC GTTCGGGCAA-3'; InvAR-5'-TCATCGCACCGTCAAAGG AACC-3' (Marlony et al. 2003), crude DNA extract ( $5 \mu \mathrm{L})$, and molecular grade water $(5.5 \mu \mathrm{L})$. Part of the inv $A$ gene has been shown to be specific for Salmonella, and if detected, it may be used to confirm the genus (Nucera et al. 2006; Rahn et al. 1992). The PCR mixture was amplified in a thermocycler (Eppendorf, Hamburg, Germany) using the following conditions: denaturation at $95{ }^{\circ} \mathrm{C}$ for $5 \mathrm{~min}, 35$ cycles of denaturation at $95{ }^{\circ} \mathrm{C}$ for $1 \mathrm{~min}$, annealing at $56{ }^{\circ} \mathrm{C}$ for $30 \mathrm{sec}$, and elongation at $72{ }^{\circ} \mathrm{C}$ for $1 \mathrm{~min}$. Final extension was done at $72{ }^{\circ} \mathrm{C}$ for $7 \mathrm{~min}$. E. coli ATCC 25922 and Salmonella Typhimurium ATCC 14028 were included as negative and positive controls, respectively. In the negative PCR control, molecular grade water was used instead of DNA.

\section{Agarose gel electrophoresis}

The PCR amplicons were subjected to electrophoresis through $1.5 \%$ ethidium bromide stained agarose gel at $3 \mathrm{~V} / \mathrm{cm}$ for $1 \mathrm{~h}$. A $100 \mathrm{bp}$ molecular weight marker was used for determining the size of amplicons. Gels were visualised under ultraviolet light and the results were recorded using a gel documentation system (BIO-RAD; Hercules, CA, USA).

\section{Ethical consideration}

This study was approved by the Agricultural Research Council. Dr Loock and Dr Mampane of Limpopo Provincial Veterinary Services offered permission to collect samples from rural abattoirs with the assistance of Mr Muthapuli.

\section{Results}

\section{Salmonella species isolated}

Table 1 shows a summary of the frequency of isolation of Salmonella on hides, carcasses, and intestinal contents and the associated serovars. On average, the frequency of Salmonella isolation on hides, carcasses, and intestinal contents was $35.37 \%(n=81)$. Most of the Salmonella were isolated from hides $(59.70 \%$; 40/67), followed by carcasses $(30 \% ; n=30)$. The frequency of occurrence of Salmonella in intestinal contents was $17.74 \%(11 / 62)$. All the Salmonella isolates had the invA gene successfully amplified.

No Salmonella was isolated from the 75 water samples. Out of the 400 freshly voided cattle faeces that were tested, $2.75 \%$ $(n=11)$ were positive for Salmonella.

TABLE 1: Distribution of Salmonella serovars according to samples types.

\begin{tabular}{|c|c|c|c|c|c|c|c|c|}
\hline \multirow[t]{2}{*}{ Samples } & \multicolumn{2}{|c|}{ Hides $\dagger$} & \multicolumn{2}{|c|}{ Carcasses: } & \multicolumn{2}{|c|}{ Intestinal Contents§ } & \multicolumn{2}{|c|}{ Faecesף } \\
\hline & $n$ & $\%$ & $n$ & $\%$ & $n$ & $\%$ & $n$ & $\%$ \\
\hline$S A b$ & 0 & 0.0 & 0 & 0 & 1 & 1.6 & 0 & 0.00 \\
\hline SA & 1 & 1.5 & 0 & 0 & 0 & 0.0 & 0 & 0.00 \\
\hline SC & 0 & 0.0 & 1 & 1 & 0 & 0.0 & 0 & 0.00 \\
\hline SE & 0 & 0.0 & 1 & 1 & 4 & 6.5 & 3 & 0.75 \\
\hline $\mathrm{SHa}$ & 1 & 1.5 & 0 & 0 & 1 & 1.6 & 0 & 0.00 \\
\hline $\mathrm{SHe}$ & 1 & 1.5 & 0 & 0 & 1 & 1.6 & 0 & 0.00 \\
\hline SM & 1 & 1.5 & 1 & 1 & 0 & 0.0 & 0 & 0.00 \\
\hline SN & 1 & 1.5 & 1 & 1 & 0 & 0.0 & 0 & 0.00 \\
\hline so & 0 & 0.0 & 0 & 0 & 1 & 1.6 & 0 & 0.00 \\
\hline SP & 1 & 1.5 & 0 & 0 & 0 & 0.0 & 0 & 0.00 \\
\hline ST & 1 & 1.5 & 0 & 0 & 0 & 0.0 & 0 & 0.00 \\
\hline SS & 0 & 0.0 & 1 & 1 & 0 & 0.0 & 0 & 0.00 \\
\hline Other & 33 & 49.2 & 25 & 25 & 3 & 4.8 & 8 & 2.00 \\
\hline Total Pos (\%) & 40 & 59.7 & 30 & 30 & 11 & 17.7 & 11 & 2.75 \\
\hline
\end{tabular}

Sab, Salmonella Aberdeen; SA, Salmonella Anatum; SC, Salmonella Cardoner; SE, Salmonella Enteritidis; SHa, Salmonella Hayindongo; SHe, Salmonella Heidelberg; SM, Salmonella Mbandaka; SN, Salmonella Nigeria; SO, Salmonella Othmarschen; SP, Salmonella Pretoria; SS, Salmonella Softenberg; ST, Salmonella Tennesse; Others, Salmonella spp.

$\dagger, n=67 ; \uparrow, n=100 ; \S, n=62 ; \uparrow, 400$. 


\section{Salmonella serovars}

Overall, out of the 92 Salmonella spp isolated from hides, carcasses, intestinal contents, and freshly voided faeces, the predominant serovar was $S$. Enteritidis $(n=8 ; 8.7 \%)$. Other serovars that were identified include, $S$. Heidelberg $(n=2$; $2.2 \%), S$. Aberdeen $(n=1 ; 1.1 \%), S$. Hayindongo $(n=1 ; 1.1 \%)$, S. Mbandaka $(n=2 ; 2.2 \%)$, S. Anatum $(n=2 ; 2.2 \%)$, S. Othmarschen $(n=1 ; 1.1 \%), S$. Nigeria $(n=2 ; 2.2 \%)$, S. Tennessee $(n=1 ; 1.1 \%), S$. Cardoner $(n=1 ; 1.1 \%)$, S. Senftenberg $(n=2 ; 2.2 \%)$, and $S$. Pretoria $(n=1 ; 2.2 \%)$. The remainder of the isolates could not be serotyped to serovar level. These Salmonella isolates belonged to OMD and OME serogroups because they reacted to these anti-Salmonella polyvalent somatic antisera. There were no monovalent antisera to further confirm the serovars of Salmonella isolates that belonged to these groups. The distribution of Salmonella serovars is summarised in Table 1.

\section{Antimicrobial resistance patterns}

Overall, $66(71.7 \%)$ of the Salmonella isolates were resistant to at least one of the tested antimicrobial agents resulting in 14 resistance patterns (Table 2). The serovars that were associated with the various resistance patterns are included in Table 2. Most Salmonella were resistant to oxytetracycline (51.90\%), followed by ampicillin (39.24\%), kanamycin (29.11\%), cefotaxime $(26.58 \%)$, and enrofloxacin $(11.39 \%)$. Multidrug resistance (resistance to $\geq 3$ antimicrobials) was observed in $25.32 \%$ of the Salmonella isolates.

\section{Discussion}

The aim of this study was to determine the contamination of hides, carcasses, and intestinal contents of cattle slaughtered

TABLE 2: Summary of antimicrobial resistance patterns of Salmonella isolates from this study.

\begin{tabular}{llc}
\hline Antimicrobial resistance pattern & Salmonella Serovars & Number of isolates \\
\hline AMP/CTX/K/OT/ENR & S. Cardoner & 1 \\
& Salmonella spp. & 1 \\
AMP/CTX/K/OT & S. Mbandaka & 1 \\
& S. Aberdeen & 1 \\
& Salmonella spp. & 14 \\
CTX/K/OT/ENR & S. Anatum & 1 \\
AMP/OT/ENR & Salmonella spp. & 1 \\
AMP/ENR & Salmonella spp. & 3 \\
K & Salmonella spp. & 2 \\
AMP & Salmonella spp. & 2 \\
ENR & Salmonella spp. & 9 \\
AMP/OT & Salmonella spp. & 0 \\
OT & Salmonella spp. & 1 \\
& S. Enteritidis & 8 \\
STX/OT & S. Heidelberg & 1 \\
AMP/K & Salmonella spp. & 11 \\
CTX & Salmonella spp. & 2 \\
K/OT & Salmonella spp. & 3 \\
OT/ENR & Salmonella spp. & 2 \\
\hline Th Salmonam & 1 \\
\hline S. Anatum & 1 \\
\hline
\end{tabular}

The Salmonella spp. could not be serotyped to serovar level using the available panel of antisera. They were identified as belonging to groups $\mathrm{OMD}$ and $\mathrm{OME}$.

AMP, ampicillin; CTX, cefotaxime; K, kanamycin; OT, oxytetracycline; ENR, enrofloxacin; S., Salmonella. in 23 rural abattoirs of Vhembe district, South Africa by Salmonella serovars, with a view to determining potential sources of contamination during cattle slaughter. All the sample types, with the exception of water were contaminated with Salmonella to varying degrees. The serovars were diverse, and most of the Salmonella belonged to group OMD and OME and they were not typed to serovar level. Numerous Salmonella serovars belong to OMD and OME groups; hence it is challenging to establish the public health significance of these isolates. Some Salmonella serovars that were observed on the cattle carcasses were not necessarily observed on the hides or intestinal contents, suggesting other potential contamination sources that were not analysed in this study. Despite extensive cattle production in rural areas, most of the Salmonella isolates were resistant to at least one of the tested antimicrobials and multidrug resistance was also observed.

The hides, carcasses, and intestinal contents of cattle in this study showed notable levels of Salmonella contamination. Salmonella isolates on the hides are usually transferred from the environment or from faecal contamination during transportation of the animals to the abattoir (Antic et al. 2010). The contamination of hides by Salmonella that was observed in this study is not unusual because it is often not practical to control Salmonella at the farm level; therefor, contaminated cattle are usually presented for slaughter (Antic et al. 2010; Bacon et al. 2000; Small et al. 2002; Vivas \& Buncic 2004). Studies involving control measures for decontamination of hides have been done, but the practicalities are uncertain (Mies et al. 2004). However, it is plausible to present relatively clean animals for slaughter to minimise the risk of carcass contamination during slaughter.

The presence of Salmonella in intestinal contents could be related to the asymptomatic carrier status of some cattle that continue to shed Salmonella without showing any clinical signs (Cummings et al. 2010). This could result in presentation of contaminated animals for slaughter, which poses a risk of transfer on carcasses. Information on the prevalence of Salmonella carrier status in African cattle is limited. In Ethiopia, Salmonella carrier status was observed to be $7.07 \%$ and $43.81 \%$ among cattle and pigs respectively (Tadesse \& Tessema 2014). These asymptomatic animals may become a source of spreading Salmonella in the herd and transmission of foodborne salmonellosis in humans.

The proportion of carcass contamination in this study was relatively high and the potential sources of contamination were diverse. The carcasses could have been contaminated during hide removal or during evisceration. Although molecular epidemiology tools such as pulsed-field gel electrophoresis and whole genome sequence analysis were not used to prove the unequivocal similarity of strains, it is highly likely that Salmonella Mbandaka and Salmonella Nigeria that were isolated from carcasses could be a result of cross-contamination from hides. Likewise, the $S$. Enteritidis on carcasses could have been transmitted from intestinal contents and faecal matter. However, S. Enteritidis is not 
regularly isolated in cattle. Nevertheless, 6 out of 232 $S$. Enteritidis from cattle, poultry, sheep, goats, and pigs were isolated from cattle in a study that was undertaken in South Africa from 1999 to 2006 (Kidanemariam et al. 2010). Use of the same equipment for slaughtering different animals and inadequate sterilisation of the utensils, which was observed during sampling, could have contributed to high chances of Salmonella contamination. In some of the abattoirs, workers sharpened knives that were used during slaughter on unconventional objects such as stones despite the potential risk of contamination. It would be paramount to study the role of such practises in Salmonella contamination of cattle carcasses. This was outside the scope of this study and constitutes a limitation of the study. Some unconventional slaughter practises in a small proportion of the rural abattoirs could have also exacerbated the frequency of carcass contamination. For instance, despite the provisions of the procedure for cattle slaughter that are elaborated in the Meat Safety Act (No. 40 of 2000), some workers in rural abattoirs still used the head of the animal as floor-support during hide removal, which increases the chances of contamination. Such unhygienic practises lead to cross-contamination by foodborne pathogens including Salmonella. This could have contributed to the inconsistent diversity of Salmonella serovars that were observed on hides, carcasses, and intestinal contents.

The separation of 'clean' and 'dirty' areas is usually proposed as one of the control measures to curb cross-contamination. However, separating 'clean' and 'dirty' areas may be extremely challenging in rural abattoirs from this study because animal slaughter took place in one room without compartments. This set-up highlights the need for strict physical and chemical decontamination programmes and regular inspection of the slaughter process as well as monitoring of the effectiveness of refrigeration of final carcass to minimise proliferation of Salmonella (Sofos \& Geornaras 2010). The use of chemical decontamination is not always acceptable in different geographical areas, and in some cases, the use of chemicals needs to be followed by rinsing of the chemicals with water (Hugas \& Tsigarida 2008). Little attention has been focused on the use of biological control such as competitive microbial cultures and bacteriophages. Despite the potential effectiveness of physical, chemical, or biological control measures, the starting-point for producing safe food should be based on good hygienic practice and good manufacturing practice that are underpinned by hazard analysis critical control points management principles (Nørrung \& Buncic 2008). In addition, training of both food handlers and consumers plays an important role in overall food safety.

Our findings are in contrast with a recent study that was conducted in abattoirs that slaughter cattle and pigs in Vhembe district, South Africa where Salmonella were not isolated (Tanih et al. 2015). The different findings could be because of the variation in number of abattoirs, source of animals, and types of samples. In addition, different isolation approaches were used. Compared to Tanih et al. (2015), our protocol used a relatively larger sample volume $(25 \mathrm{~mL})$ for pre-enrichment in buffered peptone water. In addition, this study used both MKTT and RVS for selective enrichment and XLD, BGA, and RapidSal agar for culture that increases the likelihood for the recovery and detection of Salmonella species.

In the current study, it was demonstrated that Salmonella isolates were shed in faeces of cattle from communities in areas that supply rural abattoirs in Vhembe district, which poses a potential environmental health risk. This is particularly important because it was observed that cattle manure was used for boosting growth of vegetables such as cabbage, which may be consumed raw as salads. In addition, Salmonella-infected cattle may pose a risk as they may cause cross-contamination during slaughter.

In this study, diverse Salmonella serovars were isolated from cattle hides, carcasses, intestinal contents, and faeces. S. Anatum, S. Tennessee, and S. Pretoria were isolated from hides, but were not isolated from the carcass and intestinal contents. This indicates possible environmental contamination. In a similar study, $S$. Anatum was isolated from hides, faeces, and subiliac lymph nodes (Gragg et al. 2013). Salmonella Anatum was the predominant serovar found in a study in Ethiopia that was aimed at determining antimicrobial resistance profiles and Salmonella serovars in slaughterhouse personnel, the environment in the slaughterhouse, and beef cattle (Sibhat et al. 2011). Although S. Anatum, S. Tennessee, and S. Pretoria have been rarely linked to clinical cases, S. Anatum was implicated in the infection of a patient who consumed contaminated unpasteurised orange juice (Krause, Terzagian \& Hammond 2001). Salmonella Tennessee was deemed the causative agent of a nationwide outbreak of salmonellosis in the USA, which was likely linked to environmental contamination of a peanut butter plant (Sheth et al. 2011). Salmonella Enteritidis was found on one of the carcasses, four intestinal contents, and three cattle faecal samples. It is likely that the $S$. Enteritidis was transmitted from the intestinal contents, but this finding needs to be confirmed by strain typing techniques such as pulsed-field gel electrophoresis and whole genome sequence analysis. Globally, salmonellosis in humans has been associated with $S$. Enteritidis and $S$. Typhimurium (Hendriksen et al. 2011). The presence of S. Cardoner and $S$. Senftenberg on two carcasses from this study, but not on the hides or intestinal contents, highlights the presence of other sources of contamination that were not analysed in this study. Although the information about clinical cases related to $S$. Cardoner and S. Senftenberg is scant, it is paramount to be vigilant about hygiene in order to reduce the risk of infection, particularly among individuals who may be immunocompromised.

Most Salmonella in this study were resistant to OT. Tetracycline resistance among food production animals has been attributed to selection pressure exerted from diverse sources such as prophylaxis, veterinary therapy, and use of antibiotics for 
animal growth promotion (Chopra \& Roberts 2004; Khachatourian 1998). The mechanisms of antimicrobial resistance may be broadly divided into genetic and phenotypic. Genetic resistance may be because of chromosomal mutation, or acquired genes that are harboured on transposons or plasmids (Khachatourian 1998). Tetracycline resistance may occur through tetracycline modification, ribosome protection, and tetracycline efflux (Chopra \& Roberts 2004).

Multidrug resistant Salmonella were predominant in this study. This finding is significant because antimicrobial resistance carrying plasmids could be co-localised with virulence genes, which enhances invasiveness of the bacteria (Brichta-Harhay et al. 2011; Helms, Simonsen \& Molbak 2004). This could further complicate management of infection associated with multidrug resistant Salmonella. Multidrug resistant foodborne pathogens from carcasses highlight the risk associated with the challenge of treating both human and animal infections. The situation may be exacerbated in immunocompromised individuals who are usually highly susceptible. Our findings are in harmony with observations of multidrug resistant Salmonella isolated from meat and environmental sources in other studies (Poppe et al. 2005).

The presence of multidrug resistant Salmonella pathogens warrants further investigation into general cattle farming practices and handling of veterinary drugs that might contribute to selection pressure in animals that are raised using extensive farming. The results further warrant a holistic and multidisciplinary approach to biosecurity and safety. It would be interesting to establish if there is any association between the antimicrobial resistance and virulence genes in the Salmonella isolates from this study in future. It is important to determine the serovars of all OMD, OME Salmonella groups for epidemiological purposes. In addition, it is paramount to establish the Salmonella pulsotypes and compare the patterns to those found in humans and other geographical areas. Further studies are required to study the contamination of cattle carcasses by Salmonella and the different serovars that are involved in different regions of South Africa. It would be important to determine the link between similar serovars using technologies with higher resolution such as whole genome sequence analysis.

\section{Conclusion}

The hides of cattle presented for slaughter in rural abattoirs of Vhembe district are highly contaminated with Salmonella and this may pose a risk of carcass contamination during slaughter. Some asymptomatic cattle presented for slaughter contribute to carcass contamination because of Salmonella in the intestines that has a high chance of being transferred onto the carcass. This could be exacerbated by not following proper slaughter procedure in some of the abattoirs. The differences among Salmonella serovars on hides, carcasses, and intestinal contents illustrates that there are other sources of contamination during slaughter. Antimicrobial resistance among Salmonella from cattle and environmental samples of Vhembe district was high. This poses a risk to consumers because the Salmonella may proliferate along the food value chain. Together, there is a need for regular assessment and inspection during animal slaughter in Vhembe district rural abattoirs.

\section{Acknowledgements}

This work was supported by the Red Meat Research and Development Trust under cost centre 11/04/C246 and National Research Foundation-Technology and Human Resources for Industry Programme under grant TP2011071300017. The work was done at the Agricultural Research Council-Onderstepoort Veterinary Institute. We are grateful to Dr Loock and Dr Mampane for giving permission to access rural abattoirs in Vhembe district and for allocating Mr Muthaphuli to assist with abattoir identification and sample collection.

\section{Competing interests}

The authors declare that they have no financial or personal relationships which may have inappropriately influenced them in writing this article.

\section{Authors' contributions}

E.M. was the project leader, responsible for experimental and project design and performed some of the experiments; D.K. and A.K.G. were responsible for performing some of the experiments.

\section{References}

Acha, P.N. \& Szyfres, B., 2001, 'Salmonellosis', in Zoonoses and communicable diseases common to man and animals, pp. 233-246, Scientific and Technical Publication No. 580, Pan American Health Organization, Washington, DC.

Alexander, K.A., Warnick, L.D. \& Wiedmann, M., 2009, 'Antimicrobial resistant Salmonella in dairy cattle in the United States', Veterinary Research Communication 33, 191-209.

Antic, D., Blagojevic, B., Ducic, M., Nastasijevic, I., Mitrovic, R. \& Bucic, S., 2010 'Distribution of microflora on cattle hides and its transmission to meat via direct contact', Food Control 21, 1025-1029.

Arthur, T.M., Bosilevac, J.M., Brichta-Harhay, D.M., Kalchayanand, N., Shackelford, S.D., Wheeler, T.L. \& Koohmaraie, M., 2007, 'Effects of a minimal hide wash cabinet on the levels and prevalence of Escherichia coli O157:H7 and Salmonella on the hides of beef cattle at slaughter', Journal of Food Protection 70, 1076-1079.

Bacon, R.T., Belk, K.E., Sofos, J.N., Clayton, R.P., Reagan, J.O. \& Smith, G.C., 2000 'Microbial populations on animal hides and beef carcasses at different stages of slaughter in plants employing multiple-sequential interventions for decontamination', Journal Food Protection 63, 1080-1086.

Brichta-Harhay, D.M., Guerini, M.N., Arthur, T.M., Bosilevac, J.M., Kalchayanand, N. Shackelford, S.D., Wheeler, T.L. \& Koohmaraie, M., 2008, 'Salmonella and Escherichia coli 0157:H7 contamination on hides and carcasses of cull cattle presented for slaughter in the United States: An evaluation of prevalence and bacterial loads by immunomagnetic separation and direct plating methods', Applied and Environmental Microbiology 74, 6289-6297.

Brichta-Harhay, D.M., Arthur, T.M., Bosilevac, J.M., Kalchayanand, N., Shackelford, S.D., Wheeler, T.L. et al., 2011, 'Diversity of multidrug-resistant Salmonella enterica strains associated with cattle at harvest in the United States', Applied and Environmental Microbiology 77, 1783-1796.

Buzby, J.C. \& Roberts, T., 2009, 'The economics of enteric infections: Human foodborne disease costs', Gastroenterology 136, 1851-1862.

Chopra, I. \& Robert, M., 2004, 'Tetracycline antibiotics: Mode of action, applications, molecular biology and epidemiology of bacterial resistance', Microbiology and Molecular Biology Reviews 65, 232-260.

Cummings, K.J., Warnick, L.D., Elton, M., Grohn, Y.T., McDonough, P.L. \& Siler, J.D., 2010, 'The effect of clinical outbreaks of salmonellosis on the prevalence of fecal Salmonella shedding among dairy cattle in New York', Foodborne Pathogens and Disease 7, 815-23.

Davies, R.H., Dalziel, R. \& Gibbens, J.C., 2004, 'National survey for Salmonella in pigs, cattle and sheep at slaughter in Great Britain (1999-2000)', Journal of Applied Microbiology 96, 750-760. 
Economou, V. \& Gousia P., 2015, 'Agriculture and food animals as a source of antimicrobial-resistant bacteria', Journal of Infection and Drug Resistance 8, 49-61.

Fegan, N., Vanderlinde, P., Higgs, G. \& Desmarchelier, P., 2005, 'A study of the prevalence and enumeration of Salmonella enterica in cattle and on carcasses during processing', Journal of Food Protection 68, 1147-1153.

Gragg, S.E., Loneragan, G.H., Nightingale, K.K., Brichta-Harhay, D.M., Ruiz, H., Elder, J.R. et al., 2013, 'Substantial within-animal diversity of Salmonella isolates from lymph nodes, feces, and hides of cattle at slaughter', Applied and Environmental Microbiology 79, 4744-4750.

Hammarstrom, E. \& Ljutov, V., 1954, 'Concentration technique for demonstrating small amounts of bacteria in tap water', Acta Pathologica et Microbiologica Scandinavia 35, 365-369.

Helms, M., Simonsen, J. \& Molbak, K., 2004, 'Quinolone resistance is associated with increased risk of invasive illness or death during infection with Salmonella serotype Typhimurium', Journal of Infectious Disease 190, 1652-1654.

Hendriksen, R.S., Vieira, A.R., Karlsmose, S., Lo Fo Wong, D.M.A., Jensen, A.B., Wegener, H.C. et al. 2011, 'Global monitoring of Salmonella serovar distribution from the World Health Organization Global Foodborne Infections Networ country data bank: Results of quality assured laboratories from 2001 to 2007', Foodborne Pathogens and Disease 8, 1-14.

Henton, M.M., Eagar, H.A., Swan, G.E. \& Vuuren, M., 2011, 'Antimicrobial management and resistance in livestock production. Part VI', South African Medical Journal 101, 583-586.

Hugas, M. \& Tsigarida, E., 2008, 'Pros and cons of carcass decontamination: The role of European Food Safety Authority', Meat Science 78, 43-52.

Hui, Y.H., 2012, Handbook of meat and meat processing, 2nd ed., p. 42, CRC Press Taylor \& Francis Group, Boca Raton, USA

Käsbohrer, A., Tenhagen, B-A., Appel, B. \& Fetsch, A., 2010, 'Development of harmonised survey methods for food-borne pathogens in foodstuffs in the European Union', Scientific report submitted to EFSA, viewed 04 January 2016 from http://www.efsa.europa.eu/en/supporting/pub/83e.htm

Khachatourian, G.G., 1998, 'Agricultural use of antibiotics and the evolution and transfer of antibiotic-resistant bacteria', Canadian Medical Association Journa 159, 1129-1136.

Kidanemariam, A., Engelbrecht, M. \& Picard, J., 2010, 'Retrospective study on the incidence of Salmonella isolations in animals in South Africa', Journal of the South African Veterinary Medical Association 81, 37-44.

Krause, G., Terzagian, R. \& Hammond, R., 2001, 'Outbreak of Salmonella serotype anatum infection associated with unpasteurized orange juice', Southern Medical Journal 94, 1168-1172.

Majowicz, S.E., Musto, J., Scallan, E., Angulo, F.J., Kirk, M., O’Brien, S.J., Jones, T.F., Fazil, A. \& Hoekstra, R.M., 2010, 'The global burden of nontyphoidal Salmonella gastroenteritis', Clinical Infectious Disease 50, 882-889.

Marlony, B.M., Hoorfar, J., Bunge, C. \& Helmuth, R., 2003, 'Multicentre validation of the analytical accuracy of Salmonella PCR: Towards an international standard', Applied Environmental Microbiology 69, 290-296.

Mies, P.D., Covington, B.R., Harris, K.B., Lucia, L.M., Acuff, G.R. \& Savell, J.W., 2004 'Decontamination of cattle hides prior to slaughter using washes with and without , antimicrobial agents', Journal of Food Protection 67, 579-582.

Nørrung, B. \& Buncic, S., 2008, 'Microbial safety of meat in the European Union', Mea Science $78,14-24$
Nucera, D.M., Maddox, C.W., Hoien-Dalen, P. \& Weigel, R.M., 2006, 'Comparison of API $20 E$ and invA PCR for identification of Salmonella enterica isolates from swine roduction units', Journal of Clinical Microbiology 44, 3388-3390.

Poppe, C., Martin, L.C., Gyles, C.L., Reid-Smith, R., Boerlin, P., McEwen, S.A. et al., 2005, 'Acquisition of resistance to extended-spectrum cephalosporins by Salmonella enterica subsp. enterica serovar Newport and Escherichia coli in the Salmonella enterica subsp. enterica serovar Newport and Escherichia coli in the
turkey poultry intestinal tract', Applied and Environmental Microbiology 71, turkey poulty

Rahn, K., De-Grandis, S.A., Clarke, R.C., McEwen, S.A., Gala, J.E., Ginocchio, C. et al., 1992, 'Amplification of an invA gene sequence of Salmonella Typhimurium by polymerase chain reaction as a specific method for detection of Salmonella', polymerase chain reaction as a specific
Molecular and Cellular Probes 6, 271-279.

Sheth, A.N., Hoekstra, M., Patel, N., Ewald, G., Lord, C., Clarke, C. et al., 2011, 'A national outbreak of Salmonella serotype Tennessee infections from contaminated peanut butter: A new food vehicle for salmonellosis in the United States', Clinical peanut butter: A new food vehicle
Infectious Disease 53, 356-362.

Sibhat, B., Molla, Z.B., Zerihun, A., Muckle, A., Cole, L., Boerlin, P. et al., 2011 'Salmonella serovars and antimicrobial resistance profiles in beef cattle, slaughterhouse personnel and slaughterhouse environment in Ethiopia', Zoonoses slaughterhouse personnel and s

Skov, M.N., Andersen, J.S., Aobo, S., Ethelberg, S., Aarestrup, F.M., Sorensen, A.H. et al., 2007, 'Antimicrobial drug resistance of Salmonella isolates from meat and humans, Denmark', Emerging Infectious Diseases 13, 638-641.

Small, A., Reid, C.A., Avery, S.M., Karabasil, N., Crowley, C. \& Buncic, S., 2002, 'Potential for the spread of Escherichia coli 0157, Salmonella and Campylobacter in the lairage environment at abattoirs', Journal of Food Protection 65, 931-936.

Sofos, J.N. \& Geornaras, I., 2010, 'Overview of current meat hygiene and safety riks and summary of recent studies on biofilm, and control of Escherichia coli $\mathrm{O} 157 \mathrm{H7}$ in nonintact, and Listeria monocytogenes in ready-to-eat, meat products', Meat Science 86, 2-14.

Standing Committee of Analysts, The Microbiology of Drinking Water, 2006, 'Methods for the isolation and enumeration of Salmonella and Shigella by selective enrichment, membrane filtration and multiple tube most probable number techniques', Methods for the Examination of Waters and Associated Materials, in this series, Environment Agency, Part 9, pp. 7-16, Bristol, United Kingdom.

Tadesse, G. \& Tessema, T.S., 2014, 'A meta-analysis of the prevalence of Salmonella in food animals in Ethiopia', BMC Microbiology 14, 270.

Tanih, N.F., Sekwadi, E., Ndip, R.N. \& Bessong, O., 2015, 'Detection of pathogenic Escherichia coli and Staphylococcus aureus from cattle and pigs slaughtered in abattoirs in Vhembe district, South Africa', The Scientific World Journal 2015, 1-8.

Troutt, H.F. \& Osburn, B.I., 1997, 'Meat from dairy cows: Possible microbiological hazards and risks', Revue Rcientifique et Technique 16, 405-414.

Velge, P., Cloeckaert, A. \& Barrow, P., 2005, 'Emergence of Salmonella epidemics: The problems related to Salmonella enterica serotype Enteritidis and multiple antimicrobial resistances in other major serovars', Veterinary Research 36, 267-288.

Vivas, A.L. \& Buncic, S., 2004, 'Potential for use of hide-carcass microbial counts relationship as an indicator of process hygiene performance of cattle abattoirs', Food Protect Trends 24, 814-820.

Water Research Commision No TT117/99., 2000, Quality of domestic water supplies: Sampling guide, Pretoria, South Africa. 